\title{
Teaching Reform and Innovation of Literature Retrieval Course Under SPOC Background
}

\author{
Xuehua Peng \\ Library, Zaozhuang University, Zaozhuang, Shandong277160, China \\ Email:zzxypxh@163.com
}

\begin{abstract}
This article analyzes the advantages of the literature retrieval course in the context of SPOC, and explores the reform ideas of the literature retrieval course, that is, the hybrid teaching method combining the SPOC network teaching platform and traditional conventional teaching. It also proposes reform and innovation measures from the aspects of changing students' learning thinking, teachers' information teaching ability, scientific setting of teaching content, case teaching, practical activities, and practical appraisal methods. Keywords: literature retrieval, teaching reform, SPOC teaching mode
\end{abstract}

\section{INTRODUCTION}

In the context of the education information age, the static and simplistic traditional literature retrieval teaching model has been after failing to meet the needs of informatization teaching in modern colleges and universities, and the learning needs of modern students, reform of teaching is imminent. The mixed teaching model composed of the integration of the SPOC platform in the MOOC era and the digital teaching resource platform combines the advantages of online courses and face-to-face courses.It provides new ideas and reform paths for literature retrieval teaching. The term SPOC was first coined by professors Armando Fox and David Patterson of the University of California, Berkeley in 2013 [1]. SPOC is the English abbreviation of Small Private Online Course. Compared with MOOC largescale open online education course, SPOC proposed another new form of online education-small-scale private online courses. SPOC is a small-scale private online course formed by setting admission conditions (mainly for students of our school). It is a localized learning mode of MOOC. The SPOC model can not only solve the problems that the MOOC model cannot avoid, but also further stimulate the subjective initiative of the teaching teachers to participate in teaching. At the same time, it promotes the teaching reform of the traditional teaching model, improves the teaching quality and teaching effect, and is a sustainable development of MOOC. mode.

\section{ADVANTAGES OF LITERATURE RETRIEVAL COURSE TEACHING IN SPOC BACKGROUND}

\subsection{Promote Teachers' Active Learning and Improve Information Literacy}

In the context of SPOC, in addition to having solid professional knowledge to respond to students' questions during online classroom communication, teachers must also have certain information technology capabilities, such as making video courses and completing the installation and debugging of electronic handwriting boards. Teachers should carefully design the relevant teaching content of the SPOC course, such as recording videos, designing questions, exercises, and organizing group learning to promote students' learning efficiency [2]. Therefore, teachers need to take the initiative to learn new educational technology and incorporate the latest educational technology into their professional knowledge system in time to be competent for teaching in the new situation. At the same time, we must continuously learn new teaching skills and methods and receive re-education in a targeted manner to improve our information quality.

\subsection{Breaking Time and Space Restrictions to Facilitate Autonomous Learning}

Based on the SPOC platform, it integrates the online teaching and learning environment and covers the entire teaching process. It integrates curriculum construction, resource management, mobile learning, communication and interaction, online classroom, and other functions to provide professional services for online teaching and teaching management. Teachers can organize and manage teaching 
content, answer questions online, receive and correct assignments online, organize online exams, and analyze students' learning situations on the Internet. Students can independently select teaching resources in the online platform for auxiliary learning according to their actual conditions, and participate in teaching activities and collaborative exchanges anytime, anywhere. This largely makes up for the lack of traditional teaching methods, breaks through the time and space limitations of traditional teaching, and fully realizes autonomous and open teaching with students as the main body.

\subsection{Strong Interaction Performance, Good for Communication and Collaboration}

The online teaching platform provides multiple ways for teaching interaction. Currently, the main interactive application sections include homework, teaching Q \& A, chat rooms, message boards, topic discussions, e-mail, online classroom and group pages, etc. The various communication sections are Teachers and students provide a space for communication without geographical restrictions, which facilitates real-time and non-real-time interactive communication and online Q \& A. Effectively motivate students to learn from each other and learn from each other in communication; teachers have also changed from the instructors of traditional curriculum content to the guides of students' knowledge-seeking process [3].

\section{TEACHING MODEOF LITERATURE RETRIEVAL COURSE UNDER SPOC BACKGROUND}

SPOC is a new type of online course platform. Traditional educational concepts and education models have gradually changed under the SPOC environment.The online communication module of the course can realize the instant communication and exchange between the trainee and the lecturer, or start discussions in groups. At the same time, you can also use virtual community tools to assist teaching as shown in Figure 1. Literature search is a similarity search, unlike some subjects with specific answers. Different retrieval topics will encounter different problems, which requires the establishment of a teacher-student communication platform with the help of a reference consultation mode, and can use the current popular P2P information exchange platform for auxiliary consultation [4].

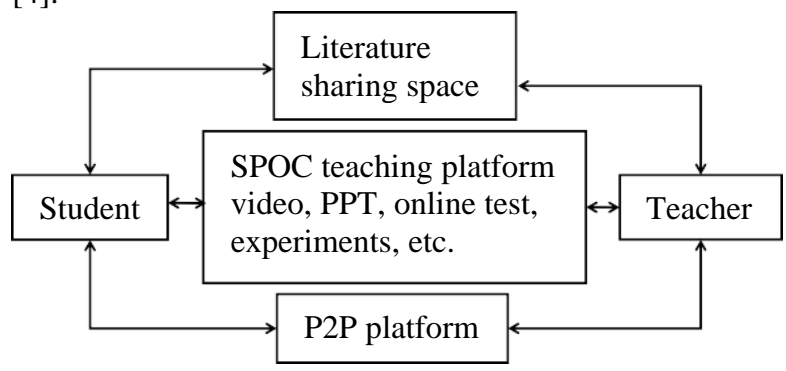

Figure 1 SPOC network teaching platform

For the literature retrieval course, the mixed teaching method that combines the online SPOC platform mode and traditional conventional teaching can be used as shown in figure 2 below. The SPOC platform mainly includes teaching content videos, online tests and discussions on topics. Definitive discussions are initiated by teachers and topics are raised for each topic. Students participate in the discussion. At the same time, students can freely exchange learning experiences and experiences in this discussion area. The online exam is an auxiliary to the offline final exam. It mainly takes the form of objective questions, and the system randomly generates and grades the questions. The scores of the online exams and the quizzes, assignments, and discussions of each unit will be proportionally included in the student's final grade.

The online course mainly completes comprehension, memory, and some applications. Traditional offline offline teaching can be used for higher-level ability training, such as application, analysis, evaluation, and creativity. Since the content taught in traditional classrooms has been recorded as instructional videos, and students are required to finish watching it outside the classroom, the main content of teachers' offline classrooms has changed significantly from the past. The teacher simply sorts out the knowledge points in the online video according to the learning level and style of the class being taught, and points out the key points and difficulties; answering questions based on the problems that occur during the online learning of the class students, helping students master all the knowledge; will be online The content taught in the course is transformed into students' own knowledge and skills.

The combination of the online SPOC platform model and traditional conventional teaching enables the information retrieval course to integrate the real experience of students in the traditional teaching environment and the flexibility and openness of the online teaching environment to improve the information retrieval and acquisition for users in the big data environment. Capabilities provide a strategy. In the teaching of information retrieval courses, the combination of knowledge transfer, collaborative learning problem solving and the cultivation of comprehensive quality are closely combined to achieve an optimized combination of teaching methods, taking into account the characteristics of groups and personalized learning needs, enhancing the attractiveness of the curriculum and improving The teaching effect is a new attempt in the reform of information quality education, and it will need continuous efforts and exploration in the future. 


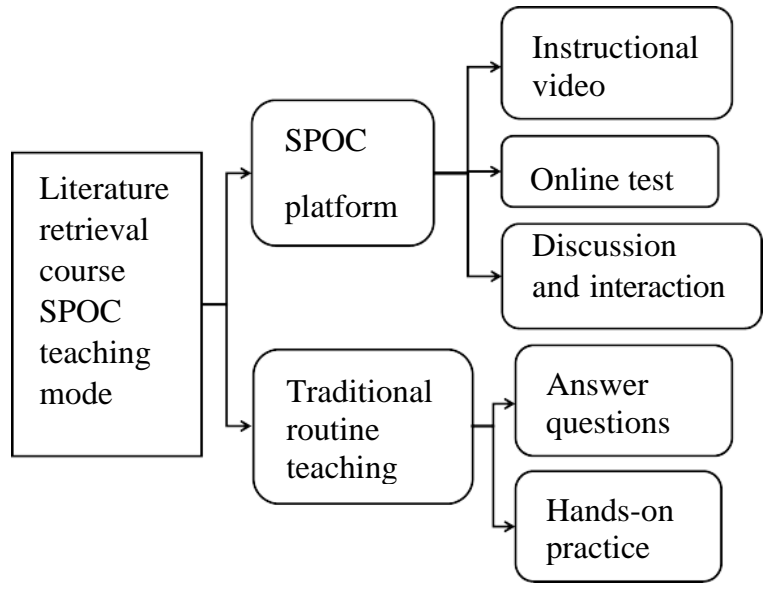

Figure 2 Teaching mode of literature retrieval course in the context of SPOC

\section{MEASURES FOR SPOC TEACHING REFORMAND INNOVATIONIN LITERATURE RETRIEVAL COURSE}

\subsection{Reform the Online and Offline Interaction Mode and Change the Students' Learning Thinking}

In the teaching process of the information retrieval course, teachers play the role of organizer, mentor, helper, and facilitator, and students are the subjects of learning. Change the teacher's thinking pattern that dominates all matters of the course, give full play to the strength of the teaching team and the initiative of students, and incorporate real-time interaction. Designate a responsible teacher who manages the online discussion area, responsible for the daily maintenance of the discussion area, and the training and management of "student assistants"; after selecting formal training, "student assistants" can be selected. After the formal training, the student assistants can assist teachers to answer questions online Interaction [5]. Give full play to students 'initiative, enthusiasm and pioneering spirit, so that students truly become the subject of learning, and cultivate students' autonomous learning ability.

\subsection{Improve Teachers' Information-Based Teaching Ability and Integrate Online and Offline}

The combination of SPOC and traditional conventional teaching provides new opportunities for document retrieval teachers, as well as new challenges. We should accelerate the improvement of our information-based teaching capabilities, adapt to new teaching models, and explore teaching methods that meet the needs of students and their expertise. Teachers must continue to learn and update their knowledge structure in order to meet the needs of students' knowledge and cognition. You can learn new knowledge and skills through self-study, advanced studies, training, correspondence, and on-the-job degree studies. You can also provide information services by participating in research topics to improve research capabilities and overall quality, and improve teaching organization. At the same time, set up a teaching team, give full play to the team's strength, divide labor and cooperate, prepare lessons collectively, avoid repeated labor, and also learn from each other strengths.

\subsection{Scientifically Set the Teaching Content and Implement the Classification of Teaching Objects}

Take hierarchical teaching to meet the teaching needs of students at different levels. According to the special requirements of each specialty and the needs of students at different levels, the literature retrieval course is divided into multiple levels. For example, students of each specialty and level have formulated syllabuses and teaching plans, and determined the corresponding teaching materials. It is also possible to divide the teaching object into three types according to the different grades and different knowledge structure of students' ability of literature retrieval, namely first-year undergraduate students, third-year undergraduate students and graduate students. First-year undergraduates will learn to use the library's basic resources (including paper literature resources and Chinese electronic literature resources). At the same time, they will learn to use the search engine for literature-assisted retrieval. The third-year undergraduate students mainly master the acquisition of electronic resources in Chinese and foreign languages, are proficient in using three major Chinese databases, are proficient in using full-text databases in foreign languages, and use the abstract (citation) database for topical searches. They learn to acquire the required documents in the shortest time and at the lowest cost. Graduate students already have the basic skills of literature retrieval. The teaching of graduate students must be based on literature retrieval to assist in subject research, to train graduate students' ability to evaluate and analyze literature, and how to use literature retrieval tools to open questions.

\subsection{Carry Out Practical Activities to Promote Teacher-Student Interaction}

Promote the teaching of the course with the technology search contest. The science and technology search contest can enhance students 'understanding and integration of the theoretical teaching content of each course of document information retrieval and information organization, and comprehensively exercise students' practical ability, communication ability, expression ability, organization ability, analysis and problem solving ability, while enhancing students' competitiveness. 
Carry out extracurricular interest activities to increase students' interest in learning. Under the guidance of the teacher, the students analyze the topics provided by the teacher, formulate the retrieval strategy and use various retrieval systems to perform the retrieval. The content of classroom teaching is further consolidated and strengthened through the development of extracurricular interest activities, and students' abilities in all aspects are effectively trained and improved.

In the process of teacher-student interaction, listen to students' opinions and suggestions. It is very important to obtain students' feedback on teaching in a timely manner, such as the hot spot they care about and the difficulties and doubts in the retrieval process.It is important to establish multichannel and multiform communication channels between teachers and students, such as classroom questionnaires,e-mail, online forums, individual conversation, etc, collect topics of interest to students as retrieval topics, and combine collaborative learning methods to enhance student interest and improve teaching quality.

\subsection{Use Case teaching to Improve Teaching Effect}

The case teaching method is a teaching method that guides students to discuss these special situations by describing a specific educational situation [6]. The case teaching method is used in the Chinese and foreign language database retrieval teaching. The purpose is to use the Chinese and foreign language database retrieval case as the basic material under the guidance of the teacher. The purpose is to use the Chinese and foreign language database retrieval case as the guidance of the teacher. Basic materials, change the traditional teacher-centered teaching method, through the interaction between teachers, students, and students, equal dialogue and discussions, increase students' interest in learning Chinese and foreign medical database retrieval and search engines, change student attitudes, and make students truly master the methods of finding and collecting literature for Chinese and foreign databases such as CNKI, Pub Med, etc. for specific scientific research topics, and train students to comprehensive skills such as professional retrieval ability, problem analysis and problem solving ability through the implementation of teaching cases.

\subsection{Practical Appraisal Methods}

The ultimate goal of the literature retrieval course is the students' practical retrieval ability and application. The assessment method should mainly reflect the hands-on ability.The evaluation method of the dedication retrieval course can abandon the traditional closed-book examination method, and mainly adopts the summary examination method, multiple evaluation methods, collaborative group cooperation methods for students, and online evaluation mode. Taking a topic search report or review as an assessment method reflects the application of information quality to practice, and also lays the foundation for writing a dissertation.

The assessment methods for different objects can also be different. The first-year undergraduates mainly conduct independent learning based on the videos and courseware provided. They can take the exam to open the book borrowing function of the campus card when they reach a certain score. There are two types of assessment for the third-year undergraduate students, namely the ordinary experimental results (50\% of the total score) and the final search report results $(50 \%$ of the total score).The assessment of postgraduates is mainly for the purpose of opening questions. In combination with the research direction of the topic, the search tools are used to find the research situation and literature, and submit a review of related topics.

\section{CONCLUSION}

In summary, compared to the large-scale and openness of MOOC, the core concept of the SPOC teaching model is tailored online courses for a specific group of small groups, and it can effectively make up for the limitations of the MOOC model and traditional teaching. As a core course of general education, information retrieval course is a tool course to improve students' information quality, selflearning ability and innovation ability. Attempts to combine SPOC and traditional conventional teaching in a ubiquitous learning environment are of great significance for stimulating students' subjective initiative in learning, improving information quality and innovation ability.

\section{REFERENCES}

[1] W. Li, H. Bingjia, Study on Teaching Reform of Information Retrieval Course in under SPOC (Small Private Online Course ) Perspective, Sci-Tech Information Development \& Economy, 2015, 25 (11), pp. 108-110.

[2] W. Biwei, Research on Teaching Reform of Information Retrieval Course under MOOC Background, Sci-Tech Information Development \& Economy, 2015, 25 (10), pp. 139-140.

[3] L. Xiaojie, Analysis of problems and countermeasures of college English teaching practice based on SPOC and flipped classroom, Journal of Neijiang Normal University, 2020, 35 (01), pp. 84-88. DOI: 10.13603/j.cnki.51-1621/z.2020.01.014

[4]X. Chun, Practice and Exploration on Teaching Reform of Information Retrieval Course in China Pharmaceutical University, Information Research, 2014, (08), pp. 66-68. DOI: 10.3969/j.issn.10058095.2014.08.018 
[5] Z. Mei, Z. Panfeng, G. Xiangfei, Q. Xu, H. Xiaoyu, Blackboard Network Platform-based Medical

Information Retrieval of International Students , Journal of North China University of Science and

Technology(Social Science Edition), 2018, 18 (05), pp. 100- 104.

[6] L. Haixia, L. Aijing, H. Dehua, Exploration and Practice of Teaching Reform of Document Information Retrieval Course - Taking the Department of Medical Information of Xiangya Medical College of Central South University as an Example, Information Research, 2011, (06), pp. 87-89. DOI:10.3969/j.issn.1005-

8095.2011.06.033. 